The International Journal of

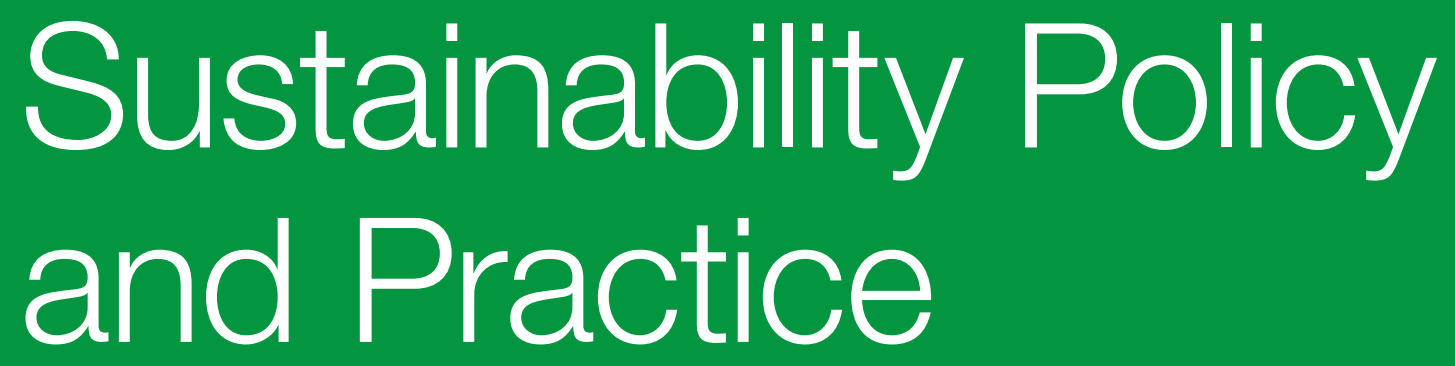

The Role of Cultural Resources in Community Sustainability

Linking Concepts to Practice and Planning

NANCY DUXBURY AND M. SHARON JEANNOTTE 
THE INTERNATIONAL JOURNAL OF SUSTAINABILITY POLICY AND PRACTICE

http://onsustainability.com/

First published in 2013 in Champaign, Illinois, USA

by Common Ground Publishing

University of Illinois Research Park

2001 South First St, Suite 202

Champaign, IL 61820 USA

www.CommonGroundPublishing.com

ISSN: 2325-1166

(C) 2013 (individual papers), the author(s)

(C) 2013 (selection and editorial matter) Common Ground

All rights reserved. Apart from fair dealing for the purposes of study, research, criticism or review as permitted under the applicable copyright legislation, no part of this work may be reproduced by any process without written permission from the publisher. For permissions and other inquiries, please contact <cg-support@commongroundpublishing.com>.

The International Journal of Sustainability Policy and Practice is a peer-reviewed scholarly journal. 


\title{
The Role of Cultural Resources in Community Sustainability: Linking Concepts to Practice and Planning
}

\author{
Nancy Duxbury, Centre for Social Studies, University of Coimbra, Portugal \\ M. Sharon Jeannotte, Centre on Governance, University of Ottawa, Canada
}

\begin{abstract}
While there is growing international policy attention to the place of culture in sustainability, and 'four pillar' local sustainability planning frameworks such as Canada's Integrated Community Sustainability Plans encourage communities to integrate culture into local sustainability planning, both conceptual and pragmatic issues challenge these efforts. At present, thinking about culture in a community sustainability context is emergent and diversely conceived, and the elaboration of a 'culture and sustainability' paradigm is not yet fully coherent. It is informed by UNESCO's statements on the contributions of cultural diversity to sustainable development, the recovery of historical and culturespecific approaches and worldviews, and local-level community development trends. Further conceptual development and clarification is required, and efforts must also be made to link the conceptualization efforts into policy/planning practice and on-the-ground actions. Towards elaborating a 'culture and sustainability' planning/policy paradigm, this paper outlines the international emergence and evolution of initiatives to integrate culture into local sustainability planning, examines important conceptual influences on understanding the role of cultural resources in sustainability, and highlights conceptual and pragmatic issues that challenge planning and policy efforts.
\end{abstract}

Keywords: Culture and Sustainability, Community Sustainability Planning, Urban Planning

\section{Introduction}

$\mathrm{W}$

hile there is growing international policy attention to the place of culture in sustainability, and 'four pillar' local sustainability planning frameworks such as Canada's Integrated Community Sustainability Plans encourage communities to integrate culture into local sustainability planning, both conceptual and pragmatic issues challenge these efforts.

At present, thinking about culture in a community sustainability context is emergent and diversely conceived, and the elaboration of a 'culture and sustainability' paradigm is not yet fully coherent (Duxbury, Cullen and Pascual 2012). Policy and planning initiatives are informed by UNESCO's statements on the contributions of cultural diversity to sustainable development, the recovery of historical and culture-specific approaches and worldviews, and local-level community development trends. Overall, further conceptual development and clarification is required, and efforts must also be made to link the conceptualization efforts into policy/planning practice and on-the-ground actions.

Rooted in observations and assessments of the inclusion of culture in local sustainability plans and related initiatives to date, this article examines the challenge of conceptualizing culture within community sustainability planning based on a review of leading European and Canadian initiatives.

\section{Tracing the Evolving Initiatives Linking Sustainability Planning and Culture}

Sustainability, as defined at the UN Conference on Human Environment in Stockholm (1972) and in the report of the World Commission on Environment and Development, Our Common Future (1987), focuses on physical ecology, and environmental concerns continue to be the

The International Journal of Sustainability Policy and Practice

Volume 8, 2013, onsustainability.com, ISSN: 2325-1166

(C) Common Ground, Nancy Duxbury and Sharon Jeannotte, All Rights Reserved

Permissions: cg-support@commongroundpublishing.com 
cornerstone of sustainable development. As the concept has matured, however, increasing emphasis has been placed on interconnections with social and economic dimensions of development, and space has opened up for debate and further reflection (Kadekodi 1992; Nurse 2006).

Culture has been the underdeveloped component of both conceptual and planning frameworks for long-term community well-being and sustainability. While conceptual work is ongoing, the inclusion of culture in policy and planning contexts has occurred in roughly three phases, tentatively designated as: (1) 2000-02 - Initial initiatives to differentiate culture from social (Australia, New Zealand, Asia); (2) 2004-06 - Initiatives closely or directly informed by the earlier developments, primarily focusing on local development (Australia, New Zealand, Small Island Developing States, Canada, UNESCO); and (3) 2008-09 - Expanded actors and a new wave of attention to advancing the place of culture within sustainability, especially at national and transnational levels (Sweden, England, Canada - Quebec, UNESCO, UCLG). Given the number and diversity of developments, they cannot all be described here. This section aims to sketch the overall terrain, highlighting key features of selected initiatives.

Figure 1. Three phases of cultural inclusion in sustainability planning

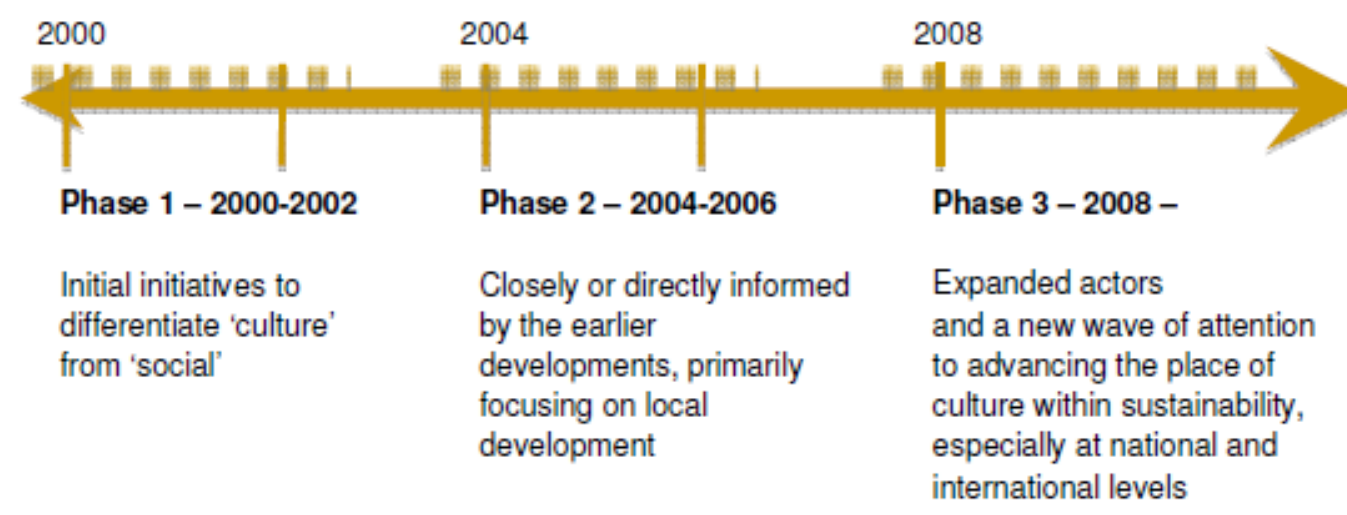

\section{Phase 1: 2000-02 - Differentiating 'Culture' from 'Social'}

During this phase, the prevailing approach to cultural considerations (if included at all) was to slot them under the umbrella of social sustainability. For example, Stren and Polèse (2000) defined social sustainability as "fostering an environment conducive to the compatible cohabitation of culturally and socially diverse groups while at the same time encouraging social integration, with improvements in the quality of life for all segments of the population" (pp. 1516). They also refer to "policies and institutions that have the overall effect of integrating diverse groups and cultural practices in a just and equitable fashion” (p. 3). Specific features and capabilities of cultures were rarely fleshed out in this context; culture's inclusion often felt like an 'add on'.

As sustainability became the prevailing framework for both local and more macro planning and policy contexts in the late 1990s, concerns about the relative neglect of cultural considerations in sustainability discourses and conventions grew. This discomfort gave impetus to grassroots thinking that fuelled the development of a four-pillar model of sustainability. Three 
parallel developments in the Pacific and Asian regions marked the beginning of more focused policy and planning attention to culture within initiatives on sustainable cities/communities. ${ }^{1}$

First, a major Asian research project (2000-02), the Kanazawa Initiative, highlighted the neglect of cultural considerations in sustainability and city-planning literatures, and examined the place of culture in building sustainable Asian cities. The project consolidated and strengthened the movement for "culturally oriented sustainable urbanization" and provided "starting points for initiating discussions and debates on an alternative urban theory and future: a "cultural theory of sustainable urbanization"” (Nadarajah and Yamamoto 2007: 11). It articulated a three-dimension view of sustainability involving environmental, economic, and socio-cultural domains, the latter defined as a system that "seeks to enrich the human dimension by harmonizing social relations and cultural pluralism” (p. 21). The project also developed the Kanazawa Resolutions, a political praxis integral to the initiative.

Secondly, in Australia, cultural experts and theorists, recognizing culture's importance in community sustainability and well-being, began waging a campaign to have it included as one of the pillars of sustainability. The Cultural Development Network commissioned Jon Hawkes' The Fourth Pillar of Sustainability: Culture's Essential Role in Public Planning (2001). Rooted in ideas from a range of international agencies and researchers, the model of sustainability it outlined incorporated four interlinked dimensions: environmental responsibility, economic health, social equity, and cultural vitality.

Thirdly, in New Zealand, a new Local Government Act was adopted (2002) which stated that local government was responsible for promoting "the social, economic, environmental, and cultural well-being of communities, in the present and for the future” (NZMCH 2006a: 1). This holistic view of community well-being was influenced by Maori worldviews, perspectives, and planning initiatives.

\section{Phase 2: 2004-06 - Focusing on Local Development}

This phase featured a series of initiatives informed by the 2000-02 developments, incorporating a four-dimension framework within an overarching umbrella of sustainability or well-being. The Australia Council for the Arts' Arts and Wellbeing (2004) included a section on ecologically sustainable development. The New Zealand Ministry for Culture and Heritage published arrays of indicators on the four well-beings of communities, including indicators relating to culture (2006a). Canadian federal policy encouraging the development of Integrated Community Sustainability Plans for cities and communities, based on a four-pillar framework, was introduced (Canada 2005). Nurse (2006) adopted and extended the four-pillar model of sustainability, applying it to the development situation and policy concerns of Small Island Developing States. In England, the Sustainable Culture, Sustainable Communities toolkit was developed for the Thames Gateway North Kent region (2006).

At the international level, UNESCO's Convention on the Protection and Promotion of the Diversity of Cultural Expressions (2005) mentioned the relation between culture and sustainable development in two articles:

- Article 2, paragraph 6, "Principle of sustainable development": "The protection, promotion and maintenance of cultural diversity are an essential requirement for sustainable development for the benefit of present and future generations."

- Article 13, "Integration of culture in sustainable development": "Parties shall endeavour to integrate culture in their development policies at all levels for the

\footnotetext{
${ }^{1}$ The Tutzinger Manifesto in Germany (2001) also reacted to this neglect, advocating for attention to the development potential of the "cultural-aesthetic dimensions" of sustainability. The Manifesto was directed to UNESCO Johannesburg conference participants, and did not reference other cultural policy/planning domains.
} 
creation of conditions conducive to sustainable development and, within this framework, foster aspects relating to the protection and promotion of the diversity of cultural expressions."

This period also saw the launch of UNESCO's Decade of Education for Sustainable Development (2005-14), which referenced environmental, economic, social, and cultural sustainability.

\section{Phase 3: 2008-Present - Rearticulating Culture within Sustainability at National and Transnational Levels}

Recently, a third wave of initiatives aimed at further conceptualizing and advocating for culture within sustainability at international and transnational levels has emerged. Three UNESCOrelated initiatives are notable: the development and approval of operational guidelines for Article 13 of UNESCO's 2005 Convention; a UNESCO Experts Meeting that considered the four-pillar model of sustainability in developing a new cultural policy profile (2009); and, more recently, the organization of an International Congress and the adoption of the Hangzhou Declaration: "Placing Culture at the Heart of Sustainable Development Policies" in May 2013. These actions are contextualized by a gradual recognition by the UN General Assembly of the importance of culture in sustainable development, marked by resolutions in 2010 and 2011, and a general desire internationally to include a cultural goal in the post-2015 development agenda. Also at an international level, the United Cities and Local Governments organization has played a key role conveying the views of local authorities, publishing a report (UCLG 2009) and adopting the resolution "Culture: Fourth Pillar of Sustainable Development" in November 2010. The AsiaEurope Foundation launched a series of initiatives focusing on culture and sustainability with an emphasis on artistic inquiry and practices (ASEF 2011), and various initiatives emerged in conjunction with the Rio+20 Conference in June 2012. At a national or subnational level, initiatives have included: the Swedish Association of Local Authorities and Regions (SALAR) position paper on Culture in the Sustainable Society (2008), and a provincial sustainability action plan based on a four-pillar model (Notre culture, au coeur du développement durable: plan d'action de développement durable 2009-2013), developed by the Province of Quebec, Canada (2009).

\section{Important Conceptual Influences on the Role of Cultural Resources in Sustainable Communities}

In our research on culture and sustainability we have seen cultural resources treated in a number of interrelated ways: as capital, as process and way of life, as a vehicle for sustainable values, as creative expression, and as complex networks. While researchers are examining these approaches and attempting to organize this 'pluralized' situation, there is a general recognition that multiple perspectives on culture are inherent to this topic.

\section{Culture as Capital}

Within the sustainability field, culture has often been discussed in terms of cultural capital, defined as "traditions and values, heritage and place, the arts, diversity and social history" (Roseland et al. 2005: 12). We inherit this stock of tangible and intangible cultural capital from past generations and pass it onto future generations. This view is prominent in discussions of built heritage within the context of sustainable development planning (e.g., Gražulevičiūtè 2006). Although the value of cultural capital may not always be measurable in terms of money, both tangible and intangible cultural assets are considered as capital that has value. As Throsby (1999) argued, cultural capital is situated within "cultural 'ecosystems' [that] underpin the operations of 
the real economy" and "neglect of cultural capital ... will likewise cause cultural systems to break down, with consequent loss of welfare and economic output” (p. 9).

Examinations of culture as capital are often undertaken by those who link culture primarily to economic sustainability, and the focus is usually on tangible cultural assets, such as buildings or artworks. Investment arguments based on cultural capital tend to be popular with politicians and decision-makers, particularly when the benefits can be translated into monetary terms, such as increases in cultural tourism. However, there are dangers in linking cultural capital too closely to economic arguments, which may neglect the intangible aspects of the 'cultural ecosystems' referenced by Throsby. For example, increases in cultural tourism may threaten fragile cultural assets, such as historical ruins, to such an extent that the economic benefits are negated by the damage to the assets themselves.

\section{Culture as Process and Way of Life}

Both Hawkes (2001) and Nurse (2006) argue that it is critical to move beyond talking only about "the arts," "heritage," and "cultural industries" and to include broader notions of culture as a "whole way of life" in discussions of sustainability. Hawkes (2006) described culture as the ways that "we make sense of our lives together, or in more formal terms, as the social production of meaning" (p. 2). By "moving beyond a focus on professional arts production, this view allows the cultural perspective to facilitate the democratic generation and expression of society's values and aspirations through creative participation” (p. 9). Doubleday, Mackenzie, and Dalby (2004) argued that discussions of sustainability must include dynamic understandings of the particular complexities of culture as well as of the place in which it occurs, so that community and geographic contexts are fully incorporated. Complementary to this perspective, culture is viewed as an adaptive and iterative process "born wherever humans had to work out a relationship with nature and themselves" (Nadarajah 2000); a "formalization of practices by individuals and/or communities as they adjust to, survive, and prosper in special contexts" (Rana and Piracha 2007: 22). Along these lines, and overlapping with the next category, many researchers are exploring how ideas of sustainable living and development are embodied in cultural and moral values and practices of societies (past and present) (e.g., Davies and Brown 2006; Paliwal 2005; Tiwari 2007; Yan et al. 2008).

\section{Culture as a Vehicle for Sustainable Values}

The elements of our habitus - how people view the world around them, their philosophy and ethics, traditional knowledge, and symbolic relationships with each other and their environment have been found to be critical factors in the sustainability of individual communities (Berkes 1998). Rana and Piracha (2007) positioned culture as "the glue that binds together all other concerns": "culture provides the building blocks of identity and ethnic allegiances and moulds attitudes to work. It underlies political and economic behaviour. Most importantly, it builds the values that can drive collective action for a sustainable future in the new global context” (p. 21). The development of "cultures of sustainability" is the focus of a wide spectrum of academic and activist efforts. For example, Brocchi (2008) identifies "ways of thinking” and a range of “capabilities” that support a more sustainable approach to the environmental crisis.

\section{Culture as Creative Expression}

Related to "culture as a vehicle for sustainable values," this category focuses primarily on art practices and works addressing environmental and sustainability-related themes and concerns, and highlights art as a vehicle for transmission of observations, insights, and knowledge. For example, EcoART collaborations merge comprehensive research with visual art and ecological interventions that aim to restore relationships between "the physical ground and the humans 
inhabiting that ground” (Carruthers 2006: 7). Themes of community engagement and awareness, education, preservation, and conservation are common. The field of ecocriticism, with "one foot in literature and the other on land" (Glotfelty and Fromm 1996: xix), aims to "bring "literary insight to nature and ecological insight to cultural production” (York University 2010).

\section{Culture as Complex Networks}

More recently, we have also started to see cultural resources described as central elements of complex networks of interdependent social and economic systems. From this perspective, the connections among diverse types of cultural resources are just as important as each node in the network. Kagan and Hahn (2011), Savova (2011), and Worts (2011) examine this concept from various angles to illustrate how it ties culture to sustainability. Kagan and Hahn suggest that a new literacy of sustainability must be attentive to complexity and to non-linear logics grounded in diversity and in cross-pollination between different social networks and urban contexts. Savova emphasizes that grassroots networks are critical to the sustainability of a community, noting that cultural planning must be sensitive not only to interconnections among network nodes, but must also take into account lapse of time (longer-term vision), looseness (responsive to the local environment), and locality (context). Worts looks at culture as an adaptive process, rather than a product or a class of products, and examines culture's role in the adaptive renewal of human societies - a role that he considers to be grounded in relationships and complex feedback loops and linkages.

These five elements of cultural resources are often combined and can emerge in quite diverse ways depending upon the lens through which they are viewed. For example, the noted planner, Charles Landry, has used this definition:

Cultural resources are the raw material of the city and its value base; its assets replacing coal, steel or gold. Creativity is the method of exploiting these resources and helping them grow. The task of urban planners is to recognize, manage and exploit these resources responsibly. (Landry 2003:13-14)

This economic perspective views cultural resources primarily as capital assets that promote the economic sustainability of a community.

Another definition of cultural resources appears in a toolkit for cultural planners published by the Creative City Network of Canada:

Understanding culture and cultural activity as resources for human and community development, rather than merely as cultural "products" to be subsidized because they are good for us, unlocks possibilities of inestimable value. And when our understanding of culture is inclusive and broader than the traditionally Eurocentric vision of "high culture," then we have increased the assets with which we can address civic goals. (Russo and Butler 2007:1)

This definition takes a more nuanced view of cultural resources as capital, emphasizing their potential contribution to the social and civic sustainability of a community. It combines a capital perspective with one which contains anthropological elements, looking at culture as both a means of expression and a way of life. These definitions illustrate that cultural planners can look at cultural resources in quite different ways and that the definition adopted can have an impact on the role that culture is seen as playing in a community. 


\section{Cultural Resources in Community Sustainability Planning Processes: Some Pioneering Examples}

Governments and organizations in a variety of jurisdictions have been attempting to bridge the gap between theories and practice with regard to culture and sustainability. This section provides an overview of several of these initiatives, as well as a tentative critique of the approaches and frameworks used to guide actions in this area.

\section{Canada}

In 2005 Canada's federal government introduced Gas Tax Agreements in support of community infrastructure investment, under which the federal government began to share with municipalities a portion of the federal tax on gasoline. The Agreements were conditional upon preparation of Integrated Community Sustainability Plans (ICSPs) - overarching documents, informed by sustainability principles, intended to encourage a more long-term and participatory approach to planning and to align municipal plans and policies under one integrated decision-making framework (Hawke-Baxter and Purcell 2007; see also Canada 2005).

The ICSPs were to be based on a 'four pillar' approach to community sustainability. While the federal government acknowledged that the cultural dimension of sustainability was not welldefined or understood, it nevertheless articulated its importance:

as Canadian communities become increasingly diverse, culture plays an important role in building social cohesion, a sense of community and a shared value set that is rooted in local diversity. Cultural investments can reinforce place-based community development objectives related to employment and innovation, neighbourhood revitalization and environmental sustainability. (Canada 2005: 12)

Several provinces, territories, and non-profit organizations developed guides to aid municipalities in developing ICSPs, which provide interesting perspectives on how culture might be incorporated into sustainability planning at the local level.

As part of our ongoing research in this area, we examined 17 guides for producing local community sustainability plans to determine if and how the fourth pillar of sustainability culture - was integrated into the overall framework (Duxbury and Jeannotte 2012). We found that fewer than half the guides defined what they meant when they discussed inclusion or integration of culture within community sustainability plans. Even fewer mentioned key aspects or notable local cultural contexts that might influence how communities deal with culture in their plans. There was no shared understanding of how to define 'culture' in this context. Those planning guides offering a definition of culture provided a broad range of interpretations, from the anthropological (focused on community identity and values) to the expressive (focused on both heritage infrastructure and a range of arts and culture activities and resources) to a combination of the two (focused on both anthropological aspects, such as language, beliefs, and ways of living together, and ways that society expresses itself through the arts and letters).

Most ICSPs developed by individual communities accepted that culture constitutes the fourth pillar of sustainability. Most of them cited a rationale for including it and provided advice on various techniques to elicit cultural input to the plan. However, the inclusion of cultural considerations was typically less developed than the other domains and varied widely in conceptualization and scope. The conceptual 'unsettledness' in this area tends to lead to further ambiguity in terms of its integration into overall community planning. 


\section{Quebec, Canada}

In 2009, the Province of Quebec developed a provincial sustainability action plan based on a four-pillar model. Notre culture, au coeur du développement durable set out in graphic form yet another variation of the familiar four-dimensional model and established several priorities for the Province's cultural ministry over the 2009-13 period. An Agenda 21 for Culture initiative based loosely on the UCLG model (2004) was developed and used as a basis for extensive community consultations throughout the province in 2011. In December 2011, the province released a set of principles and an action plan intended to make culture a central element of its sustainability policies (QMCCSW 2011).

\section{New Zealand}

New Zealand was one of the earliest jurisdictions to adopt the four-pillar model and to apply it to community sustainability/well-being. Like Canada, it has attempted to operationalize its wellbeing model by requiring local authorities to produce Long-Term Council-Community Plans (LTCCP) that integrate and interconnect cultural, social, economic, and environmental wellbeing. This planning effort is notable in that it provided some guidance to local governments on how cultural well-being interacts with the other three dimensions, and an overview of resources to assist local governments in the development of their LTCCPs (NZMCH 2006a, 2006b).

Despite this support, the Ministry for Culture and Heritage's 2005 scan of LTCCPs found as we did in our assessment of Canadian ICSPs - a variety of inconsistencies and ambiguities with regard to the treatment of cultural well-being. For example, many councils mixed discussions of social and cultural well-being and appeared to have difficulties in capturing cultural well-being objectives and outcomes (NZMCH 2006a), suggesting that a clear path between conceptual clarity and strategic sustainability planning had not yet been achieved.

\section{Sweden}

The Swedish Association of Local Authorities and Regions 2008 position paper, Culture in the Sustainable Society, took a broad approach to the topic of sustainability, and discussed the importance of culture for local and regional growth, social sustainability, and the creation of an attractive and sustainable living environment. It also addressed governance and educational issues related to culture and sustainability, suggesting that "national cultural policy must be created by municipalities, county councils and central government together" (p. 17) and recommending that Regional Development Plans become the vehicles for negotiations and agreements with the central government on cultural support to the regions. Like Quebec's action plan on sustainable development, the Swedish document is intended as a blueprint for political action at the national and regional level. It advocates for culture's role in long-term sustainable development, but does not provide details that could guide local planners in operationalizing that role.

\section{United Kingdom}

In 2004, the U.K. Department for Culture, Media and Sport published a document entitled Leading the Good Life - Guidance on Integrating Cultural and Community Strategies in response to changes to the planning framework in the U.K. Local Government Act of 2002, which eliminated the requirement that local authorities produce a Local Cultural Strategy and directed them to subsume cultural strategies within a Community Plan. Leading the Good Life provided a blueprint for integrating community and cultural planning. This was supplemented by an initiative called "Where we live!", launched in 2006 "to articulate the value of culture to sustainable community planning and devise strategies to provide the full range of cultural 
benefits for as many communities as possible over the long term” (UKDCMS 2006). As with the Canadian ICSPs, supporting documentation provided some guidance on definitions of culture and sustainable communities. However, the documents do not furnish a great deal of information to assist local authorities in integrating culture within sustainability plans.

In 2006, a more detailed operational guide, Sustainable Culture, Sustainable Communities, was produced for the Thames Gateway North Kent region. The document provided rationales for investing in culture, an assessment of the local cultural sector, a vision and 24 principles to guide future cultural development, and a set of recommendations for strategic planning. The guiding principles were intended as a checklist to help planners "understand and assess cultural projects with a view to maximising cultural value, and maximising the benefits of public investment" (p. viii). Sustainability was primarily tied to cultural infrastructure development, with a secondary emphasis on developing "successful communities where bonds between people are forged and strengthened" (p. viii).

\section{Conclusions}

As our analysis indicates, the relationships among culture, sustainability and communities (particularly community planning initiatives) is still very much a work in progress. Therefore, our conclusions are tentative and couched in provisional terms.

We have examined writings on culture and sustainability since 2000 from around the world and have been struck by their diversity and complexity. There is value in bringing these perspectives and initiatives together and in recognizing and highlighting cross-threads of common concerns. Despite our focus in this article on the elements of planning and development, we believe that there is a need to dig deeper into the research emanating from a variety of disciplines and locales and to develop more cross-disciplinary and transnational linkages so that these perspectives can better inform each other. While cross-threads and common concerns can provide valuable insights, the possibility exists that the "shock of the new" can also usefully inform our ideas about culture and sustainability. Ironically, this shock can also come when we discover that some elements of our emerging conceptual framework for culture and sustainability are rooted in the very old - traditional holistic models that the modern world has almost forgotten but that were central to the sustainability of ancient cultures and societies.

We are also aware that most of the work that we have highlighted emanates from Englishspeaking countries. Therefore we believe that it will be important to investigate more of the literature from Latin America, which appears to focus on "culture in development" and "cultural/biological diversity linkages" discourses, and from francophone countries, which appears to be more closely linked to Agenda 21 for Culture.

With regard to the pragmatic aspects of this topic, our preliminary research has revealed rather weak linkages between the conceptual underpinnings of culture and sustainability and community planning praxis. Culture-related planning and policy practices are as yet only weakly situated within a sustainability context. In our own research, we are committed to an in-depth review of the ICSPs developed in Canadian communities, and intend to pursue a parallel scan and analysis of urban sustainability plans, policies, guides, and related initiatives developed by European cities and city-networks. We are hopeful that further work in this area will be forthcoming, and welcome both suggestions and collaborative initiatives. 


\section{REFERENCES}

ASEF (Asia-Europe Foundation) (2011), Arts. Environment. Sustainability. An overview of ASEF projects. Singapore: Connect2Culture program, ASEF.

Australia Council for the Arts (2004), Arts and wellbeing. Sydney: ACA.

Berkes, F. (1998), Cultural and natural capital: A systems approach revisited, in A. Mendis (ed.), Social capital formation and institutions for sustainability. Vancouver: University of British Columbia.

Brocchi, D. (2008), The cultural dimension of sustainability, in S. Kagan and V. Kirchberg (eds.), Sustainability: A new frontier for the arts and culture. Frankfurt: Verlag für Akademische Schriften, 26-58.

Canada, Government of (2005), Integrated community sustainability planning - a background paper. Prepared for Planning for Sustainable Canadian Communities Roundtable, organized by the Prime Minister's External Advisory Committee on Cities and Communities.

Carruthers, B. (2006), Mapping the terrain of contemporary ecoart practice and collaboration. Prepared for "Art in Ecology - A Think Tank on Arts and Sustainability,” Vancouver.

Davies, W.K.D.; Brown, D.F. (2006), Culturing sustainability: Towards frameworks of understanding, in J. Chi-Kin Lee; M. Williams (eds.), Environmental and geographic education for sustainability: Cultural contexts. New York: Nova Science, 23-38.

Doubleday, N.; Mackenzie, F.; Dalby, S. (2004), Reimagining sustainable cultures: constitutions, land and art, Canadian Geographer, 48(40): 389-402.

Duxbury, N.; Cullen, C.; Pascual, J. (2012), Cities, culture and sustainable development, in H.K. Anheier; Y.R. Isar; M. Hoelscher (eds.), Cultural policy and governance in a new metropolitan age. The Cultures and Globalization Series, Vol. 5. London: Sage.

Duxbury, N.; Jeannotte, M.S. (2012), Including culture in sustainability: an assessment of Canada’s Integrated Community Sustainability Plans, International Journal of Urban Sustainable Development, 4(1): 1-19.

Glotfelty, C.; Fromm, H. (eds.) (1996), The ecocriticism reader. Athens: University of Georgia Press.

Gražulevičiūtè, I. (2006), Cultural heritage in the context of sustainable development, Environmental Research, Engineering and Management, 3(37): 74-79.

Hawke-Baxter, K.; Purcell, M. (2007; November), Community sustainability planning, Municipal World, 35-38.

Hawkes, J. (2001), The fourth pillar of sustainability: Culture's essential role in public planning. Melbourne: Common Ground.

Hawkes, J. (2006), “Creative democracy,” Keynote at “Interacció ’06: Community Cultural Policies” conference, Barcelona.

Kadekodi, G.K. (1992), Paradigms of sustainable development, Journal of SID (3): 72-76.

Kagan, S.; Hahn, J. (2011), Creative cities and (un)sustainability: From creative class to sustainable creative cities, in N. Duxbury; M.S. Jeannotte (eds.), Culture and Local Governance / Culture et gouvernance locale, 3(1-2): 11-27.

Landry, C. (2003, January), Imagination and regeneration: Cultural policy and the future of cities. Strasbourg: Council of Europe, Directorate General IV - Education, Culture and Heritage, Youth and Sport.

Nadarajah, M. (2000), City, culture and sustainable development: Towards a cultural framework for sustainable urbanization, Report of the International Conference on Culture in Sustainability of Cities I. Kanazawa, Japan: IICRC, 48-61.

Nadarajah, M.; Yamamoto, A.T. (eds.) (2007), Urban crisis: Culture and the sustainability of cities. Tokyo: United Nations University Press. 
NZMCH (New Zealand Ministry for Culture and Heritage) (2006a), Cultural well-being and local government. Report 1: Definition and context of cultural well-being. Wellington: NZMCH.

NZMCH (2006b), Cultural well-being and local government: Report 2: Resources for developing cultural strategies and measuring cultural well-being. Wellington: NZMCH.

Nurse, K. (2006), Culture as the fourth pillar of sustainable development. Prepared for Commonwealth Secretariat, UK.

Paliwal, P. (2005), Sustainable development and systems thinking: A case study of a heritage city, International Journal of Sustainable Development and World Ecology, 12(2): 213220.

QMCCSW (Québec Ministry of Culture, Communications and the Status of Women) (2009), Notre culture, au coeur du développement durable: plan d'action de développement durable 2009-2013. Quebec: QMCCSW.

QMCCSW (Québec Ministry of Culture, Communications and the Status of Women) (2011), Agenda 21C - Culture aujourd'hui demain. Quebec: QMCCSW. http://agenda21c.gouv.qc.ca .

Rana, R.S.J.B.; Piracha, A.L. (2007), Cultural frameworks, in M. Nadarajah; A.T. Yamamoto (eds.), Urban crisis. Tokyo: United Nations University Press, 13-50.

Roseland, M. et al. (2005), Towards sustainable communities: Resources for citizens and their governments. Gabriola Island, BC: New Society Publishers.

Russo, A.; Butler, D. (2007). Cultural planning toolkit. Vancouver: Creative City Network of Canada and 2010 Legacies Now.

Savova, N. (2011). Arm's length and 'hand-shake' policies: Community arts alternatives to outcome-based development (insights from Brazil, Bulgaria, and South Africa), in N. Duxbury; M.S. Jeannotte (eds.), Culture and Local Governance / Culture et gouvernance locale, 3(1-2): 43-58.

Stren, R.; Polèse, M. (2000), The new sociocultural dynamics of cities, in M. Polèse; R. Stren (eds.), The social sustainability of cities: Diversity and the management of change. Toronto: University of Toronto Press.

SALAR (Swedish Association of Local Authorities and Regions) (2008), Culture in the sustainable society. Stockholm: SALAR.

Thames Gateway North Kent (2006), Sustainable culture, sustainable communities: The cultural framework and toolkit for Thames Gateway North Kent.

Throsby, D. (1999), Cultural capital, Journal of Cultural Economics, 23: 3-12.

Tiwari, S.R. (2007), Transforming cultural heritage into sustainable future: A case study of Patan, Nepal, in M. Nadarajah; A.T. Yamamoto (eds.), Urban crisis. Tokyo: United Nations University Press, 62-106.

"Tutzinger manifesto for the strengthening of the cultural-aesthetic dimension of sustainable development” (2001), developed at “Aesthetics of Sustainability” conference, Tutzing, Germany.

UCLG (United Cities and Local Governments) (2004), Agenda 21 for culture. Barcelona: UCLG.

UCLG (United Cities and Local Governments) (2009), Culture and sustainable development: Examples of institutional innovation and proposal of a new cultural policy profile. Barcelona: UCLG.

UKDCMS (U.K. Department for Culture, Media and Sport) (2004), Leading the good life guidance on integrating cultural and community strategies. London: DCMS.

UKDCMS (2006), "Cultural agencies launch joint initiative showing why culture and sport are essential to the sustainable communities agenda.” DCMS Media Release 2484.

UNESCO (2005), Convention on the protection and promotion of the diversity of cultural expressions. 
UNESCO (2013), The Hangzhou Declaration: Placing culture at the heart of sustainable development policies. Paris: UNESCO. Adopted in Hangzhou, People's Republic of China, on 17 May 2013.

World Commission on Environment and Development (1987), Our common future. New York: Oxford University Press.

Worts, D. (2011), Culture and museums in the winds of change: The need for cultural indicators, in N. Duxbury; M.S. Jeannotte (eds.), Culture and Local Governance / Culture et gouvernance locale, 3(1-2): 117-132.

Yan, Y. et al. (2008), Analysis of the role of the Mosuo culture in local environmental protection in Lugu Lake region, International Journal of Sustainable Development and World Ecology, 15: 48-55.

York University - Canada Research Chair in Sustainability and Culture (2010), Sustainability and culture: An approach. Webpage:

http://www.yorku.ca/ecocult/pages/crcapproach1.html

\section{ABOUT THE AUTHORS}

Dr. Nancy Duxbury: Nancy Duxbury, PhD, is a Senior Researcher and Co-coordinator of the 'Cities, Cultures and Architecture' research group of the Centre for Social Studies, University of Coimbra, Portugal, and a participant in the European COST Action on 'Investigating Cultural Sustainability'. She is also an Adjunct Professor of the School of Communication, Simon Fraser University, Canada. Her research interests include culture and sustainability, cultural planning and local governance, and the integration of cultural considerations within broader planning initiatives. She is internationally published, and has been a guest editor for the journals Culture and Local Governance (special double issue on 'Culture and Sustainable Communities', coedited with M.S. Jeannotte), Society and Leisure, and the Canadian Journal of Communication. She was lead author of Under Construction: The State of Cultural Infrastructure in Canada and Developing and Revitalizing Rural Communities through Arts and Creativity.

M. Sharon Jeannotte: Since 1996, my primary research focus has been on social cohesion as a horizontal public policy issue affecting Canadian society. In recent years, I have been exploring the intersections between culture and sustainability in planning and policy, with particular attention to the inclusion of culture in Canada's Integrated Community Sustainability Plans. I have published research on a variety of subjects, including the impact of value change on Canadian society, international definitions of social cohesion, the points of intersection between cultural policy and social cohesion, the role of cultural participation and cultural capital in building sustainable communities, culture and volunteering, and immigration and cultural citizenship. In 2005, I co-edited, with Caroline Andrew, Monica Gattinger, and Will Straw, a volume entitled Accounting for Culture: Thinking Through Cultural Citizenship, published by the University of Ottawa Press. I was also part of a research team studying the social effects of culture, which produced several papers that were featured by the Canadian Journal of Communication in April 2006. 
The International Journal of Sustainability Policy and Practice is one of four thematically focused journals in the collection of journals that support the Sustainability knowledge community - its journals, book series, conference, and online community.

The journal addresses sustainability agendas and the practices flowing from these in government, corporate, and community sectors.

In addition to traditional scholarly papers, this journal invites presentations of sustainability practicesincluding documentation of case studies and exegeses analyzing the effects of these practices.

The International Journal of Sustainability Policy and Practice is a peer-reviewed scholarly journal.



